\title{
Advances in lasers and optical micro-nano-systems
}

Fredrik Laurell

fllaserphysics.kth.se

Eugenio Fazio

eugenio.fazio@uniroma1.it
Laser Physics, School of Engineering Sciences, KTH - Royal Institute of Technology, Stockholm, Sweden

Dipartimento di Energetica, Sapienza Universit di Roma, Via Scarpa, 16 I-00161 Roma, Italy
Lasers represent a well consolidated technology: nevertheless, research in this field remains very active and productive, in both basic and applied directions. At the moment significant attention is given to those sources that bring together high power and compactness. Such high power lasers find important applications for material treatments and such applications are presented by Ehsani et al. [1] and Saiedeh Saghafi et al. [2], in the treatment of dielectric thin films (Alteration of optical and morphological properties of polycarbonate illuminated by visible/IR laser beams) or of biological tissues like pistachio seeds (Investigating the effects of laser beams (532 and $660 \mathrm{~nm}$ ) in annihilation of pistachio mould fungus using spectrophotometry analysis). In particular the latter paper shows how laser sources can find very important applications in new domains, preserving goods and food without the need for preservatives or pesticides by simply sterilizing them using light.

Optical Micro and Nano Systems presents a new domain for exploration. In this framework this special issue is very attractive, because it assembles papers reporting new results in three directions: new techniques for monitoring integrated micro- and nano-systems, new integrated systems and novel high performance metamaterial configurations. Integrated micro-components can be monitored and controlled using reflectance measurements as presented by Piombini et al. (Toward the reflectance measurement of micro components) [3]. Speckle formation during laser beam reflection can also be a very sophisticated tool for detecting ultra-precise displacements, as presented by Filter et al. (High resolution displacement detection with speckles : accuracy limits in linear displacement speckle metrology) [4].

Three dimensional integrated optical structures is indeed a big challenge and a peculiarity of photonics, they can be formed through traditional holography or using more sophisticated and novel technologies. Thus, special manipulation of the writing-reading optical beam can push holography toward storages at higher data densities, as presented by Norihiko Ishii et al. (Wavefront compensation method using novel index in holographic data storage) [5]. Along a similar direction Furlan et al. [6] describe a very innovative technique for producing optical traps using novel Devil micro-lenses (Volumetric multiple optical traps produced by Devil's lenses). Vynnyk et al. [7] presented an interesting application of electron microscopy for monitoring sub-micrometric structures in $3 \mathrm{D}$ configurations (3D-measurement with the stereo scanning electron microscope on sub-micrometer structure). Finally, S. Rao et al. present two interesting papers $[8,9]$ on integrated structures compatible with silicon technology: one describes the realisation of low-loss waveguides using amorphous silicon, a relatively novel material with many applications in very different domains (Low-loss amorphous silicon waveguides grown by PECVD on indium tin oxide), and one on the realisation of a electrically drivable device with affective compatibility with CMOS technology (Electro-optical modulating multistack device based on the CMOS-compatible technology of amorphous silicon).

We hope that this special issue of the Journal of the European Optical Society will reflect the interest of the European Scientific Community toward these fundamental and applied topics and will demonstrate to readers some of the actual directions of research. We express our full appreciation to the authors that participated to this initiative which acts only as a primer for the vast amount of work now being undertaken in laser physics and applications in micro- and nano-systems. We would like to give a special thank to the paper reviewers for their important role in the paper selection process and all the journal staff for their very professional support, dedication and energy, which made this special issue feasible.

\section{References}

[1] H. Ehssani, S. Saghafi, M. Choranneviss, M. Hantehzadeh, H. Hosseini, and H.-U. Dodt, "Alteration of optical and morphological properties of polycarbonate illuminated by visible/IR laser beams" J. Europ. Opt. Soc. Rap. Public. 5, 10032S (2010).

[2] S. Saghafi, R. Penjweini, K. Becker, K. W. Kratky, and H.-U. Dodt, "Investigating the effects of laser beams (532 and $660 \mathrm{~nm}$ ) in annihilation of pistachio mould fungus using spectrophotometry analysis" J. Europ. Opt. Soc. Rap. Public. 5, 100335 (2010).

[3] H. Piombini, P. Voarino, D. Breider, and F. Lemarchand, "Toward the reflectance measurement of micro components" J. Europ. 0pt. Soc. Rap. Public. 5, 10034S (2010).

[4] R. Filter, T. Scharf, and H. P. Herzig, "High resolution displacement detection with speckles : accuracy limits in linear displacement speckle metrology" J. Europ. Opt. Soc. Rap. Public. 5, $10035 \mathrm{~S}$ (2010).

[5] N. Ishii, T. Muroi, N. Kinoshita, K. Kamijo, and N. Shimidzu, “Wavefront compensation method using novel index in holographic data 
storage" J. Europ. Opt. Soc. Rap. Public. 5, 10036s (2010).

[6] W. D. Furlan, F. Gimenez, A. Calatayud, L. Remon, and J. A. Monsoriu, "Volumetric multiple optical traps produced by Devil's lenses" J. Europ. Opt. Soc. Rap. Public. 5, 10037s (2010).

[7] T. Vynnyk, T. Schultheis, T. Fahlbusch, and E. Reithmeier, “3Dmeasurement with the stereo scanning electron microscope on sub-micrometer structures" J. Europ. Opt. Soc. Rap. Public. 5, 10038s (2010).
[8] S. Rao, F. G. Della Corte, and C. Summonte, "Low-loss amorphous silicon waveguides grown by PECVD on indium tin oxide" J. Europ. Opt. Soc. Rap. Public. 5, 10039s (2010).

[9] S. Rao, and F. G. Della Corte, "Electro-optical modulating multistack device based on the CMOS-compatible technology of amorphous silicon" J. Europ. Opt. Soc. Rap. Public. 5, 10040S (2010). 